\title{
The Feel Good Factor: comparing Immersion by Design and Immersion by Default models
}

\author{
Fiona Gallagher and Angela Leahy \\ School of Applied Language and Intercultural Studies, Dublin City University, Ireland
}

\begin{abstract}
This article presents findings from an exploratory research project entitled Gaelscoileanna and Multicultural classrooms: the potential for transfer to enhance L2 learning experiences. The project focussed on two language immersion contexts in Ireland which, despite obvious differences, share a range of significant commonalities. One context was that of the Gaelscoil, where instruction is through the medium of Irish, and the other that of the mainstream English-medium school, where learners from migrant backgrounds often experience a form of language immersion which is referred to here as 'immersion by default'. The views of teachers and principals are described in this article. Data from this cohort illustrates how each school type approached the celebration of Language per se in relation to learners for whom the language of instruction is not the L1. This raises two key issues: (1) the extent to which the school can see itself as a site of and for multilingualism and (2) the extent to which learners in all immersion contexts can also be affirmed as language learners. Findings point to how immersion contexts, regardless of whether they are 'design' or 'default' in nature, can inform each other. We argue that each has the potential to approach Language in additive ways.
\end{abstract}

\section{Keywords:}

immersion, multilingualism, migration, Gaelscoil, affirmation, education

\section{Introduction and Background to Study}

The benefits of bilingual education are well documented (Bialystok, 2001; Genesee, 1987; Marsh \& Hill, 2009; Peal \& Lambert, 1962). That these benefits mainly accrue where the educational context is one of additive bilingualism, whereby the language of instruction is seen as of equal status and adding to the number of languages already known by the student, is also widely acknowledged (Cloud, Genesee \& Hamayan, 2000; Cummins, 1979, 2000; García, 2009; Genesee \& Riches, 2006; Lasagabaster, 2009; Lindholm-Leary and Howard, 2008; Thomas \& Collier, 2002). This is often contrasted to subtractive bilingualism, which is usually associated with the education of learners from migrant backgrounds where there is an implicit and sometimes explicit pressure exerted on members of the migrant community to replace the heritage language of the children with the language of instruction in school, which is also the dominant language in the host community (Banks, 2009; Cummins, 2009; Freeman, 2004; Nieto, 2004, Ó Laoire, 2012). In this paradigm, the language of school is seen as of greater value and importance for the children than their native language. Although certain cognitive benefits have been identified to a limited degree in this bilingual context also (Bialystok \& Peets, 2010), the long-term effects of the devaluing of the heritage language and culture of these children in terms of their well-being, self-esteem and sense of personal identity as well as on their general academic achievement have been highlighted and continue to be investigated (Banks, 2008; Cummins et al., 2005; Lee \& Suarez, 2009; Romaine, 2009; Suárez-Orozco \& Suárez-Orozco, 2009; Windle, 2009).

Elsewhere in research on immersion/bilingual education, there has been a more recent move to identify commonalities between the different immersion models, ranging from full immersion to asingle-subject-taught-through-an-additional-language contexts, whereby the curriculum content is delivered and accessed through a language which is not the first language of the children (Coyle, 2009; Coyle, Hood \& Marsh, 2010; García, 2009; Johnstone, 2002). The need for crossfertilisation across models in order to address certain teaching and learning issues common to the 
various contexts has been highlighted (Fortune \& Tedick, 2008; García, 2009; Hornberger \& Skilton-Sylvester, 2003). The experiences of children from migrant backgrounds in mainstream classes, when they are taught alongside children for whom the language of instruction is their first language, has been referred to as "submersion" (Freeman, 2004: 6) and in general has tended not to be included in the immersion spectrum. This paper draws on observations and findings which emerged from an exploratory research project entitled Gaelscoileanna and Multicultural classrooms: the potential for transfer to enhance L2 learning experiences. (The expression L2 is used throughout to denote any language that is not the first language of learners. It is acknowledged that for some learners Irish or English might be a third, fourth etc. language.) The project had as its key focus the comparison of two language immersion contexts in the primary school sector from the perspective of how the teaching and learning of the immersion language is perceived in them. While intuitively one might not look to pair these two contexts for the purposes of comparison, our research has shown that such a comparison is not only valid but also very fruitful in terms of its contribution to our understanding of teaching and learning in the bi-/ multilingual classroom.

By interviewing stakeholders (learners, teachers, parents and principals as well as some academic/ policy experts) who engaged with conventional language immersion in Irish medium Gaelscoileanna (Irish-medium schools, usually outside Irish-speaking areas; singular is Gaelscoil) and their counterparts who engaged with what we have termed 'immersion by default' (explained below) in mainstream English-medium schools, the research team sought to gain insights into how one model might help to inform the other from the perspective of the teaching and learning of content through an L2 and, in so doing, make a contribution to our overall understanding of factors that can affect immersion teaching and learning. The project focussed on two cohorts of learners, namely those with little or no knowledge of Irish who attend primary Gaelscoileanna and those with little or no English who attend mainstream English-medium schools. The first cohort is generally comprised of learners from Ireland who have enrolled in a Gaelscoil while the second cohort is generally comprised of learners from a migrant background who have enrolled in the more commonly found mainstream English-medium school.

Generally, learners from a migrant background receive instruction and are assessed through an L2 if they attend a mainstream school. Taking the perspective of the learner, we therefore argue that learners in this cohort experience an authentic type of language immersion which bears much resemblance to that of learners in the first cohort described above, albeit with considerable contextual differences. Having L2 and L1 speakers together in the same class is not uncommon in immersion contexts. Yet traditionally, the term 'immersion' has not been applied to contexts in which learners from a migrant background join mainstream schools and must come to terms with being educated through an L2 in much the same way as conventional immersion learners do.

From the evidence presented below, we suggest that much could be gained in both practical and theoretical terms by positioning such a type of immersion onto the increasingly stratified Language and Content spectrum that already includes such variations on a theme as Full Immersion, Twoway Immersion, Content and Language Integrated Learning and Content Based Language Teaching. We consequently propose the creation of an additional space on that spectrum as well as the introduction of new terminology which will capture the teaching and learning through an L2 that frequently presents itself in migration contexts. Concepts such as "circumstantial" (contrasted with "elective") bilingualism (Valdés, 1997: 31) do not fully capture this educational reality, and therefore, for our purposes, we have chosen to use the term 'immersion by default', which we contrast with the term 'immersion by design', to describe this context. Despite major differences, some of which are outlined above, our research points to distinct similarities which exist between 
the teaching and learning experiences in the 'immersion by design' and 'immersion by default' contexts and a corresponding potential for cross-fertilisation and transfer across the two models.

By comparing these two immersion contexts, the project aimed to identify ways in which teaching and learning through an L2 could be supported. The study involved visits by two researchers to five English-medium schools and five Gaelscoileanna in various urban locations in Ireland. The schools which responded to our call for participation varied in profile and they are therefore not intended to represent the entirety of these school types. Each school visit involved interviews using semi-structured questionnaires with two learners, two teachers, the school principal and two parents in each of the ten schools. Academic and policy experts and two Gaeltacht schools were also involved in the study. Interviews were recorded, transcribed and subjected to close reading by the researchers in order to identify recurring themes in each individual context. This was followed by comparative analysis.

Our focus was less on the micro-level pedagogical or didactic classroom strategies and methods involved in immersion instruction or on such ancillary language supports such as EAL (English as an Additional Language) tuition by withdrawal, although these are without doubt important. Instead, we focus primarily on comparing the types of attitudinal infrastructure and framing that might be provided for learners in each of the two language immersion models of interest here. We therefore address such questions as: How are language and learning through an L2 viewed in each context? How is the linguistic undertaking of the immersion learner viewed in each context? What implicit messages might immersion learners receive in the school setting? How might these issues be approached at the macro level in the schools?

For the purposes of this article, we focus solely on contributions made by teachers and principals in order to give voice to their distinct perspective and experiences as practitioners. Schools and interviewees will not be referred to in a way which will allow them to be identified and individuals will be referred to by either their role (e.g. teacher, principal) or the personal pronouns she/ her, or, in the case of learners, by a capital letter, not the first letter of their name. Where we present quotations from interviewees, we attribute these to code names, such as Teacher1-School-L or Principal-Scoil-C, whereby the letter appearing after 'School' or 'Scoil' is different to that used in the actual school name.

Findings and suggestions should be understood within the context of the exploratory nature of the project, the subjective nature of this type of research, and the small number of participants involved.

The comparison of the data provided by the Gaelscoileanna and English-medium mainstream schools provided a rich vein of analysis and yielded a number of striking observations which could certainly help inform our understanding of approaches to language immersion. This is reflected in the interview extracts presented below, many of which have been condensed for the purposes of readability and clarity. As will be seen in the next section, two aspects merited particular attention. These form the basis of the discussion which follows below. They are firstly dealt with in relation to Gaelscoileanna and then in relation to the English-medium schools.

\section{Immersion by Design: Gaelscoileanna}

As could be expected, in Gaelscoileanna there is a familiarity with what we might broadly term the 'language issues' that arise when content and language are brought together. Navigating curricular content with language issues in mind has always been a reality in 'immersion by design' contexts, 
including those contexts in which to varying degrees the immersion language may be an L1 for some students but an L2 for others. In the immersion context, language acquisition is seen as an integral part of the educational process. This implicit general acceptance of the linguistic dimensions of teaching and learning may manifest itself in various different ways.

Our analysis of the interview data provided by teachers and principals in the Gaelscoileanna revealed a number of striking features with regard to how language issues were approached. While problems and challenges experienced by teachers and learners in Gaelscoileanna were often referred to, so too were positive aspects associated with teaching and learning in this context. We focus on two of these here, namely:

- The view of the school as a site of and for bi-/ multilingualism

- The affirmation and support of learners as (amongst other things) language learners.

In many of the contributions made by teachers and principals in the Gaelscoileanna involved in our study, reference was made to the academic, intellectual, linguistic and communicative benefits of $\mathrm{bi}-/$ multilingualism and to the positive aspects that can accompany language learning in immersion contexts. It is clear that for many involved in this model of immersion, the school context offered the possibility to appreciate and celebrate Language in general (and not just Irish):

Children who have language $\mathrm{X}$ at home and language $\mathrm{Y}$ in school ... have much more positive pressure put on them to learn to focus on how they learn to concentrate on what the material is they do succeed and they succeed much better and [...] they actually succeed much better in their overall academic performances than the child [...] whose exposure is only through one language

(Principal-Scoil-C)

they have the added advantage of being bilingual ... and and you know there's intellectual development there and linguistic development and everything like that and [...] it's full development or it's going towards you know full development

(Principal-Scoil-M)

yeah well I suppose it is different but they still get a lot from it and they're practising the language and the structure of the language and they're taking part in games they're not being held back in any way either $[\ldots]$ they still get an awful lot out the way it's taught definitely

(Teacher1-Scoil-D)

the biggest thing I think cognitively you know really and truly they have to be more ... more developed I think $[. .$.$] the whole thinking you do in a different language where you would think in English and you$ would think in Irish and then you would not so much think in French but ... it's an easier state to get to when you're used to going from language to language and translating over and back [...] being open to languages being open to learning and actually in terms of processing knowledge and that dual processing ...

(Principal-Scoil-O)

A number of teachers also focussed on the fact that learning through an L2 is a linguistically enriching experience for their learners by referring to languages other than Irish. Teachers believed that learners' proficiency in English is in no way hindered by their learning through Irish and were mindful of the need to maintain linguistic development in both Irish and English:

the fact that they are learning through Irish doesn't hold them back in any way you know they get very they achieve very high scores in their reading in assessment tests in English for instance vocabulary and so on

(Teacher2-Scoil-O) 
it doesn't disadvantage their English

(Principal-Scoil-M)

we're contrasting in terms of English language work in terms of reading etc. even though we teach the curriculum and spend the recommended amount of time [...] we also believe that the children have that inherent right to have high standards of English [...] it's an expectation we have

(Principal-Scoil-D)

Other comments alluded to the multilingual benefits that learners can experience. Here, immersion education was associated with an openness on the part of learners to learn additional languages in the future:

I mean they go onto maybe a third language sometimes ... fourth you know when they go into secondary school and things like that

(Principal-Scoil-M)

an interesting point Irish has a very large number of sounds [...] if children are exposed to Gaeilge and good sounding of the words it's a huge benefit when they're then trying to produce some of the sounds correctly and accurately in French [...] or German or Italian whatever.

(Principal-Scoil-C) (See Hickey and Stenson (2011) for observations on Irish orthography.)

they tend to perform very well [...] but maybe have a little something on children who are in Englishspeaking schools in that they learn

Interviewer: An advantage?

A little advantage yeah in that they’ve learnt another language and they may be more receptive towards foreign languages in the future and academically in general

(Teacher1-Scoil-D)

In the context of learners from a migrant background attending Gaelscoileanna or learners without prior knowledge of Irish joining in the senior cycle, while some teachers expressed concerns around this, others were quick to see these learners as multilingual beings who adapt to the learning of Irish with a facility that they linked directly to their existing multilingual capabilities:

we always had children that were non-nationals say ... who hadn't any Irish and really it was a success story [...] their command of languages ... eh is very very positive and because they have their own language they may have you know they have English and then they have the Irish and ... so ... in this school it's very positive [...] I had an experience one time of a child he was Nigerian actually and I was amazed at how fast he picked up the language ... the Irish language ... I think it's because they are very used to different languages ... you know even within their own community there may be two or three languages ... and maybe linguistic skills are maybe more developed you know

(Principal-Scoil-M)

I would say about some of the non-nationals that they pick up the language as we tell our children most of those children have come from a country where three or four languages [...] and they don't think anything about it

(Teacher1-Scoil-C)

she was just you know she obviously she just really wanted to learn it ... and but there again there was no doubt that because of the fact that she was multilingual beforehand it certainly helped her

(Teacher1-Scoil-O)

I wonder about the assumptions teachers make about the ability of children also to acquire language [...] the possibilities of children being able to acquire language much more quickly and readily than we assume ... we have a child here who's just come from Nigeria [...] she came straight into Senior Infants she didn't have one word of Irish before she left the office on her first meeting she had five words of Irish $[\ldots]$ and this is three weeks to four weeks later $[\ldots]$ she has number systems she has greetings she 
understands classroom management directions [...] we didn't make assumptions [...] there are huge opportunities for language you know transference

(Principal-Scoil-D)

As can be seen from the contributions highlighted above, teachers and principals in the Gaelscoil setting tended to celebrate the linguistic resources of their learners and the possibilities that can present themselves for learners in that setting. Such a celebratory type of framing of the language and content learning process indicates how the schools in question can view themselves as sites of and for bi-/ multilingualism.

Somewhat related to the positive view of bi-/ multilingualism in the Gaelscoileanna is the positive view of the learner in the Gaelscoil as being a bilingual or multilingual being. There was ample evidence in the interview data of the ways in which Gaelscoileanna celebrated and supported the learners' language undertaking and development. The contributions made by teachers and principals showed how learners receive a significant amount of encouragement and support as far as their identity as individuals who are engaging with language is concerned. This affirmation of the learner as a language learner was articulated in a number of different ways, some direct and some indirect.

One of the ways in which this manifested itself was in the mindfulness of teachers with regard to issues that could affect the perceptions or feelings of learners attending a Gaelscoil. Teachers spoke about how they reflected on or addressed openly with learners any concerns they may have with regard to learning through Irish:

we make statements to the children you know at least twice a year or I do you know where are we? what are we about? are you proud of that fact? why are you proud of that fact? And to elicit that sense of pride in the children it builds up esteem in in the wider group of children that has a positive benefit for those children who are feeling you know it's not for them [...] and so any time they would would speak with parents if they're having difficulty parents would remind them of the fact of the benefits as they see them and they'll see it as a positive situation

(Principal-Scoil-D)

some of the kids will tell you "we were in Spain and we spoke a lot of Irish" [...] and I said "and was it nice to speak in your own language" "yeah it was actually" you know like they're very proud of their language when they move outside of the country but within the country some of them would kind of think well I'm not going to speak Irish here you know kind of everybody speaks is speaking in English you know that they'd be embarrassed

(Teacher1Scoil-N)

either way trying to make sure that they understand that it's a positive thing and it's great to have your own language

(Teacher2-Scoil-M)

I don't think they'd ever perceive themselves as inferior [...] and I think they're very proud of it like at senior level anyway I think even though they'd be kind of messing and they would get into trouble for speaking English I think deep down they're quite proud that they can speak Irish

(Teacher1-Scoil-M)

it shouldn't be an issue in that you know we speak Irish here and you know we talk to them a lot about it (Teacher2-Scoil-O)

Some teachers also referred to the fact that they felt that the Gaelscoil imparted more than 'just' language to its learners. They referred to how the school had a role to play in preserving heritage, thereby broadening the learning experience. In that sense, it could be seen that the Gaelscoil 
teacher can fulfil a type of supportive ambassadorial role that extends beyond her role in language and content teaching:

it's a bigger battle you know it is a bigger you know brief to take on [...] but as a teacher and as a teacher in a Gaelscoil you just buy into it and that's that's what you're there for that's what's you believe in you wouldn't be teaching in an Irish school if you didn't really feel that you wanted to them to have this new skill or new language or their their heritage

(Teacher1-Scoil-C)

they're coming with very little and I suppose there's great job satisfaction because ... you know you see everything I suppose in any junior infant class everything you teach them you see anyway and but particularly with the language when you hear them chatting through Irish in senior infants you know you've given them that ... there's that great buzz from that you know

(Teacher2-Scoil-O)

With regard to the role of the Gaelscoil in fostering a sense of identity and heritage, some teachers endorsed the decision of parents to enrol their children in Gaelscoileanna. As the following quotations reveal, the teachers in question believed that by choosing a Gaelscoil for their children, the parents wanted to provide their children with something positive that they themselves had not had:

I think a lot of people want the children to have what they don't have so I would imagine a lot of households it isn't just the people continuing [...] you have people who want to have something that they didn't have so they don't feel fluent they don't feel confident and they want the children to have Gaeilge so I would imagine that's a big part of it

(Teacher2-Scoil-C)

I teach Irish to parents in the school and it's more a choice the parents have made in a lot of cases because they haven't got the language and they would like their children to have it

(Teacher1-Scoil-D)

Teachers and principals also spoke about creating a whole-school, supportive Irish-speaking atmosphere. As can be seen from the following quotations, this can be created and maintained by exposing learners to a variety of different sources of Irish which can include teachers, older pupils and other adults:

... we try and kind of create an Irish-speaking atmosphere in every way possible [...] where we are coming from is we want to have as much as possible surrounding us and surrounding the children the children hear more than just the the teachers speaking Irish that is very important the need to hear lots of other children other adults speaking Irish as well

(Teacher1-Scoil-C)

The only thing is later on when they are mixing with other people and if Irish happens to be used they will be very they won't turn off they won't switch off for example the guard came on a visit to the school and he was able to speak Irish and they were [...] impressed [...] they couldn't get over it they turned around and they said "He has Irish?" [...] they'd be very impressed absolutely they love it [...] they really do

(Teacher1-Scoil-N)

I suppose the whole thing has been quite is always very positive and they just know [...] this is a Gaelscoil so you speak and you do everything through Irish here and we do you know that's what we do so we just get them to learn the language as quickly as possible and just keep exposing them ... to it and so on

(Principal-Scoil-O)

we place a lot of emphasis on games as Gaeilge and we have rhymes that we teach them for skipping ... and things like that ... we try our very best to implement them in the yard and we'd have children from the senior classes helping the children from the infants to rang a dó [...] that's very very effective where 
you'd have children from fifth and sixth coming out and doing like 'Deir Ó Grádaigh' and then the skipping as Gaeilge and other activities as well ... and actually the juniors actually love it

(Principal-Scoil-M) (rang a dó = second class)

In summary, our research clearly identifies the importance given by many teachers in the 'immersion by design' context to the celebration of language learning per se. It was highlighted how the school can be viewed as a site of and for bi-/ multilingualism and how learners can be affirmed as language learners in this model. Given the commonalities mentioned earlier which exist between the two contexts involved in this study, we moved to look for equivalents in the 'immersion by default' context.

\section{Immersion by Default: Learners from a Migrant Background in Mainstream Classes}

In general, the teachers and principals we spoke to in the English-medium schools viewed the range of languages used within their school community positively as a key element of the multicultural nature of the school. However, there were significantly fewer references to the language learning skills of the L2 learners in the school and, unlike in the Gaelscoil context, the children themselves did not tend to be affirmed as bi-/ multilingual beings.

Within the English medium school context, most of the schools we visited responded to the increased numbers of children from migrant backgrounds in their school by embracing the values of multiculturalism and diversity. There was a decided sense that the teachers and principals we spoke to were striving to honour the heritage culture of these children in their schools. This manifested itself in a number of ways but particularly through, for example, prayers and school signage in a variety of languages or a focus on national costumes and songs at times of celebration such as Christmas.

The role of the school in the promotion of positive civic values such as tolerance and inclusion within the school community was often referred to. Many teachers commented on their role in facilitating the integration process for these children through the ethos of the school and classroom practice in respect of playground/classroom interventions, care in relation to the grouping of children, anti-racist policies and the promotion of values of respect for all cultures and tolerance of difference within the school community. Indeed, many teachers saw their school as playing a vital part in standing against racism and intolerance in society at large:

in relation to racism which I perceive to be alive and thriving in my own little country ... in relation to combating racism schools not only can play a part I believe they are quite outstanding and are out there in front really ... I really believe that (Principal-School-L)

Perhaps inevitably, given the number of cultures and languages represented in some schools, there was a tendency to group all non-English speaking cultures together (e.g. a wall with 'Welcome' in 25 languages; children from different linguistic backgrounds, e.g. Polish-speaking and Urduspeaking children paired together in a 'buddy' system) and less attention given to the individual cultures and individual languages of these children.

The teachers were also very sensitive to the particular needs of these children and frequently mentioned how difficult it was for them in terms of how much harder they had to work in order to catch up with their peers and how lonely an environment it must be for them, especially in the beginning. Fear, confusion, frustration and self-consciousness were often mentioned in relation to older children, especially for newly-arrived older children. In general, teachers were very alive to 
the emotional and even in some cases traumatic circumstances which may have surrounded the arrival of these children in Ireland. Perhaps because of this, there was a clear emphasis on the part of teachers and principals on helping the children to settle into Irish life and society and much less on the affirmation of the individual cultural and linguistic backgrounds of these children. Interestingly, the teachers did not tend to make a distinction between assimilation and integration in this context. The following comments from teachers illustrate their perspectives in this regard:

\begin{abstract}
you know we've done things then as well to try and make the children feel as at home as much as possible [...] the longer they are here the more Irish themselves they become kind of and like they it never ceases to amaze me how they actually can integrate have integrated so well with us and have taken on our ways $[\ldots]$ and taken on $[\ldots]$ our accents and like they seem to be very content and happy here (Principal-School-P)
\end{abstract}

I'm sure it's really daunting and the whole lot but yeah they really seem integrated and they pick up [...] they all have kind of Dublin accents and stuff

(Teacher2-School-S)

I'd say this school is very inclusive and it's open to everybody to become involved and like [...] even into the music lessons and that after school ... even into the choir and that ... we do accommodate all of the children

(Teacher2-School-O)

The easing of these children into school life and Irish society in general was considered to be a priority, particularly in the short-term. However, the long-term psychological and attitudinal effects on the self-esteem and sense of well-being for many of these children were also referred to by teachers/ principals. Indeed, the teachers frequently mentioned how quiet, withdrawn and undemanding these children tended to be, how slow they sometimes were to volunteer answers and participate in class.

you know I find they're not demanding children generally... now some may be but the children I've had are not ... they quietly sit there ... and actually you'd prefer them maybe to be a bit more demanding, saying "I don't understand I don't understand" ... they don't tend to

(Teacher1-School-C)

Certainly in the first year ... it's... they are certainly affected emotionally [...]. I'd say with their small minds they don't know how to feel about themselves ... I'd say they're confused really in the beginning they don't I can't put a finger on it but it's certainly confused. It's very hard for me to say "listen, it's not your fault you don't need to worry you're not supposed to understand this yet" you know

(Teacher1-School-S)

but in general they would be kind of quieter I noticed now with some of the Polish children they would be quieter

(Teacher1-School-P)

the younger ones they experience a lot of frustration in the first year or two ... there's a little one in senior infants $[\ldots]$ very frustrated child ... last year very happy child this year ... and that would really I think be the pattern ... there's a frustration of not being able to explain and sometimes they can get aggressive or they sort of just go into themselves ... but once they actually get over that ...

(Principal-School-C)

As mentioned earlier, the celebration of multiculturalism and linguistic diversity in general was very much in evidence in the English-medium schools we visited, but much less so was the affirmation of the linguistic identities of the children themselves. 
The teachers were aware that the children did not speak English as their first language. However, they were often vague as to what the first language of a particular child was or what language was spoken in the home.

Interviewer: And what's her native language?

Teacher: Lithuanian ... or Latvian one or the oth ... Latvian I think ... one or the other ... and she has no English whatsoever

(Teacher2-School-C)

there are two languages the school would have information on that would be put to the parents ...French and do you know I ... it could be Afrikaans I don't know what the other ...

(Teacher1-School-O)

Overall, the use of the native language outside school tended to be viewed as a disadvantage, as having a detrimental effect on the acquisition of English.

but then it's very hard for them if they're speaking their national language at home and only speaking in English in school [...] they'd be much slower

(Teacher2-School-P)

many children don't speak English in their homes which is quite understandable but it presents problems. (Principal-School-L)

things would be reinforced at home but when that's not there it's very very tough (Teacher1-School-O)

Only one teacher described the importance of using a more positive vocabulary to describe the linguistic profiles of the children:

I think sometimes we really use inappropriate language. [...] unintentionally we'd say eh "you can't speak English" instead of saying "you speak Polish" [...] because these children have a full language that they can speak already... English is just their second language (Teacher1-School-S)

In fact, many of the children speak several languages in the home. Although one or two teachers referred to the bi-/ multilingual skills of these learners, in general this was not seen as something to celebrate or affirm on their behalf.

Several teachers spoke of how easily these learners picked up English:

children pick up language children of that age are like sponges they they pick up language pretty quickly anyway

(Principal-School-S)

they just take to they just absorb all the learning around them their language skills improve immensely (Principal-School-O)

and then within the space of a few months [English] just started to come and come and come (Teacher1-School-L)

But at this stage her English given that she's only here six months is quite excellent [...] her rate of progress has been stunning ... and her parents do not speak English ... it's amazing it's amazing. (Principal-School-L) 
However, there were in fact very few references to the language learning skills of the learners in general, i.e. in relation to other languages. Drawing on our findings from the Gaelscoil context, a potential way to affirm the skills of learners from migrant backgrounds relates to the ability of multilingual individuals to pick up additional languages relatively easily. One or two teachers were aware of this to some extent but most seemed not to be. Indeed, surprise at these children's facility with the Irish language was expressed very frequently. For example:

I mean he's actually doing Irish this year would you believe [...] so G. himself has got the book and he is really interested in learning it and he's actually nearly surpassed some of my weaker kids in the class already

(Teacher2-School-P)

Irish as well ... a lot of them pick it up cause ... they just pick it up

(Teacher2-School-S)

Several teachers expressed the view that learning additional languages would be very confusing for the children and place an additional burden on them:

I worry then that they can't distinguish between Irish and English

(Teacher1-School-P)

Some teachers mentioned finding other tasks for the children to do during Irish lessons. For example:

maybe instead of sitting through a very long Irish lesson I give them something, maybe handwriting practice or say a first-class spelling book for example

(Teacher1-School-S)

One teacher spoke of discouraging a student (later described as being "exceptionally bright") from learning Irish [because of her age (11 years), the child was exempt from studying Irish in school], despite the fact that the child had expressed a keen desire to do so. She "got around it" by conducting the Irish lesson for the rest of the class while the Polish-speaking child was attending her English language support class.

H. is exempt so [...] H. was off the hook. [...] and she said she'd actually like to learn some Irish so I said "look you don't have to" [...] and what I try to do the hour that she would be out with the SNA in the morning I do my Irish then so that she's not missing another hour while I do Irish ... so you know (Teacher1-School-C) (SNA=Special Needs Assistant)

The potential to affirm learners from migrant backgrounds in terms of their multilingual skills and ability to excel at languages, including Irish, seems not to feature in the data provided by the mainstream teachers involved in our study. Further, this demonstrates perhaps a missed opportunity in terms of finding possible avenues for these children to gain academic success in particular subjects at school.

A related point concerns the cognitive benefits of bilingual education. Unlike in the 'immersion by design' context, these were not referred to at all by the teachers. In fact, a certain underestimation of these learners in terms of what they might be capable of was mentioned by several teachers. For example:

but sometimes you maybe accept work and say you have to understand it's not you know it's not his first language perhaps 
Interestingly, a significant number of teachers referred to at least one learner from a migrant background in their class who they felt was extremely intelligent.

\footnotetext{
But the child I mean H. is actually exceptionally bright ... so I had you know I was lucky that she was exceptionally bright

(Teacher1-School-C)
}

I'd say if he was in Hungary he'd be super intelligent in the class

(Teacher2-School-P)

A number of factors are sure to be at play here but it is not inconceivable that these observations relate to some degree to the cognitive benefits associated with bilingual education.

\section{Conclusion}

The need for more inclusive language education policies has become apparent in ongoing discussions on multilingualism and schooling (see for example Ó Laoire, 2012). Comparisons across models, such as the two explored here, can usefully inform the framing of such policies. This study is small-scale and exploratory in nature and any conclusions drawn should be understood in that light. Nevertheless, an understanding of what we have termed 'immersion by default' and how it relates to more clearly recognised 'immersion by design' contexts raises useful questions around approaches to multilingualism in education. Further large-scale research is required to address these more fully and to identify concrete ways in which the potential for transfer across language immersion contexts could be realised.

As mentioned earlier, both contexts involved in our study share a number of commonalities as far as language immersion is concerned. This is particularly apparent when viewed from the perspective of the classroom experience of the learner: in each context, she/he is expected to access the curriculum, demonstrate knowledge and complete examinations through an L2.

However, the Gaelscoil, being an 'immersion by design' model, exhibits a number of characteristics which for a variety of reasons were not as apparent in the mainstream 'immersion by default' context. In the 'immersion by design' context, there was an appreciation of language from the outset, which resulted in the development of an infrastructure which tends to foreground L2 language learning in clearly identifiable, concrete ways, affecting many aspects of school life. This L2 language-sensitive infrastructure was made particularly visible in terms of how the school views itself as a site of and for multilingualism and in terms of how it affirms the learner as a language learner.

By seeing itself as a site of and for multilingualism and by affirming the language learning part of the learner profile, the Gaelscoil celebrates and supports the language learning endeavours of its pupils. The importance attached to this by the teachers and principals in our study was striking. However, in the 'immersion by default' context, while a range of issues relating to multiculturalism were addressed, this affirmation of L2 language learning per se and the multilingual dimensions of teaching and learning were not as apparent.

Given the clear efforts on the part of teachers and principals in mainstream schools to find ways to affirm learners from migrant backgrounds, the above findings may point to a missed opportunity 
with regard to supporting these learners. Here, reference to practice in the Gaelscoil model which supports bi-/ multilingualism could well prove fruitful. Such practice which focuses on the school as a site of and for multilingualism and the affirmation of the learner is entirely additive in nature and is therefore particularly pertinent for contexts where submersion or subtractive bilingualism could occur.

It is precisely for reasons such as the above that future research should focus on expanding the range of points on the 'Language and Content' spectrum to include contexts like 'immersion by default' which have not traditionally featured there. Otherwise such comparisons across contexts are less likely to be considered intuitive and the potential for transfer across models might remain unrealised. Consequently, practical opportunities to support migrant learners such as those identified in our study might remain untapped.

\section{Acknowledgements}

The authors gratefully acknowledge the funding which the Irish Research Council for the Humanities and Social Sciences (IRCHSS) made available for the research project which is described in this article. We would also like to express our thanks to the learners, parents, teachers, principals and academic/ policy experts who participated in this project.

\section{References}

Banks, J. A. (2008). Diversity, group identity, and citizenship education in a global age. Educational Researcher, 37(3), 129-139. doi: 10.3102/0013189X08317501

Banks, J. A. (2009). Multicultural education: Dimensions and paradigms. In J. A. Banks (Ed.), The Routledge international companion to multicultural education (pp. 9-33). New York NY: Routledge.

Bialystok, E. (2001). Bilingualism in development: Language, literacy and cognition. Cambridge: Cambridge University Press.

Bialystok, E., \& Peets, K. F. (2010). Bilingualism and cognitive linkages: Learning to read in different languages. In M. Shatz, \& L. C. Wilkinson (Eds.), The education of English language learners: Research to practice (pp. 133-152). New York: The Guildford Press.

Cloud, N., Genesee, F., \& Hamayan, E. (2000). Dual language instruction: A handbook for enriched education. Boston: Heinle and Heinle.

Coyle, D. (2009). Language pedagogies revisited: Alternative approaches for integrating language learning, language using and intercultural understanding. In J. Miller, A. Kostogriz \& M. Gearon (Eds.), Culturally and linguistically diverse classrooms: New dilemmas for teachers (pp. 172-196). Bristol: Multilingual Matters.

Coyle, D., Hood, P., \& Marsh, D. (2010). CLIL: content and language integrated learning. Cambridge: Cambridge University Press.

Cummins, J. (1979). Linguistic interdependence and the educational development of bilingual children. Review of Educational Research, 49(2), 222-251. doi: 10.3102/00346543049002222 
Cummins, J. (2000). Language, power and pedagogy: Bilingual children in the crossfire. Clevedon: Multilingual Matters.

Cummins, J. (2009). Fundamental psycholinguistic and sociological principles underlying educational success for linguistic minority students. In T. Skutnabb-Kangas, R. Phillipson, A. K. Mohanty \& M. Panda (Eds.), Social justice through multilingual education (pp. 19-36). Bristol: Multilingual Matters.

Cummins, J., Bismilla, V., Chow, P., Cohen, S., Giampapa, F., Leoni, L., Sastri, P. (2005). Affirming identity in multilingual classrooms. Educational Leadership, 63(1), 38-43.

Fortune, T. W., \& Tedick, D. J. (2008). One-way, two-way and indigenous immersion: A call for cross-fertilization. In T. W. Fortune, \& D. J. Tedick (Eds.), Pathways to multilingualism: Evolving perspectives on immersion education (pp. 3-22). Clevedon: Multilingual Matters.

Freeman, R. (2004). Reviewing the research on language education programs. In O. García, \& C. Baker (Eds.), Bilingual education: An introductory reader (pp. 3-18). Clevedon: Multilingual Matters.

García, O. (2009). Bilingual education in the 21st century: A global perspective. Chichester: Wiley-Blackwell.

Genesee, F. (1987). Learning through two languages: Studies of immersion and bilingual education. Rowley, MA: Newbury House.

Genesee, F., \& Riches, C. (2006). Literacy: Instructional issues. In F. Genesee, K. LindholmLeary, W. M. Saunders \& D. Christian (Eds.), Educating English language learners: A synthesis of research evidence (pp. 109-175). New York: Cambridge University Press.

Hickey, T. \& Stenson, N. (2011). Irish orthography: what do teachers and learners need to know about it, and why? Language, Culture and Curriculum, 24, 1, 23-46. doi: $10.1080 / 07908318.2010 .527347$

Hornberger, N. H., \& Skilton-Sylvester, E. (2003). Revisiting the continua of biliteracy: International and critical perspectives. In N. H. Hornberger (Ed.), Continua of biliteracy: An ecological framework for educational policy, research, and practice in multilingual settings (pp. 35-71). Clevedon: Multilingual Matters.

Johnstone, R. (2002). Characteristics of immersion programmes. In O. García, \& C. Baker (Eds.), Bilingual education: An introductory reader (pp. 19-33). Clevedon: Multilingual Matters.

Lasagabaster, D. (2009). Multilingual educational systems: An added challenge for immigrant students. In J. Miller, A. Kostogriz \& M. Gearon (Eds.), Culturally and linguistically diverse classrooms (pp. 18-36). Bristol: Multilingual Matters.

Lee, J. S., \& Suarez, D. (2009). A synthesis of the roles of heritage languages in the lives of children of immigrants: What educators need to know. In T. G. Wiley, J. S. Lee \& R. W. Rumberger (Eds.), The education of language minority immigrants in the United States (pp. 136171). Bristol: Multilingual Matters. 
Lindholm-Leary, K., \& Howard, E. R. (2008). Language development and academic achievement in two-way immersion programs. In T. W. Fortune, \& D. J. Tedick (Eds.), Pathways to multilingualism: Evolving perspectives on immersion education (pp. 177-201). Clevedon: Multilingual Matters.

Marsh, D., \& Hill, R. (2009). Study on the contribution of multilingualism to creativity. Brussels: European Commission. Retrieved from http://eacea.ec.europa.eu/llp/studies/documents/study_on_the_contribution_of_multilingualism_to _creativity/compendium_part_1_en.pdf

Nieto, S. (2004). Affirming diversity: The sociopolitical context of multilingual education (4th ed.). Boston: Pearson.

Ó Laoire, M. (2012). Language policy and minority language education in Ireland: re-exploring the issues, Language, Culture and Curriculum, 25, 1, 17-25. doi: 10.1080/07908318.2011.653055

Peal, E., \& Lambert, W. E. (1962). The relation of bilingualism to intelligence. Psychological Monographs: General and Applied, 76(27), 1-23. doi: 10.1037/h0093840

Romaine, S. (2009). Language, culture and identity across nations. In J. A. Banks (Ed.), The Routledge international companion to multicultural education (pp. 373-384). New York: Routledge.

Suárez-Orozco, M., \& Suárez-Orozco, C. (2009). Globalization, immigration and schooling. In J. A. Banks (Ed.), The Routledge international companion to multicultural education (pp. 62-77). New York: Routledge.

Thomas, W., \& Collier, V. (2002). A national study of school effectiveness for language minority students' long-term academic achievement. UC Berkeley: Center for Research on Education, Diversity and Excellence. Retrieved from: http://escholarship.ucop.edu/uc/item/65j213pt

Valdés, G. (1997). Bilinguals and bilingualism: Language policy in an anti-immigrant age. International Journal of the Sociology of Language, 1997(127), 25-52. doi: 10.1515/ijsl.1997.127.25

Windle, J. (2009). Influences on the written expression of bilingual students: Teacher beliefs and cultural dissonance. In J. Miller, A. Kostogriz \& M. Gearon (Eds.), Culturally and linguistically diverse classrooms: New dilemmas for teachers (pp. 92-113). Bristol: Multilingual Matters. 